\title{
Stock Market Valuation and Monopolistic Competition: a Dynamic Stochastic General Equilibrium Approach
}

\author{
Gabriel Talmain \\ University of Glasgow
}

\begin{abstract}
This paper extends a Real Business Cycle model to an economy in which monopolistic competitive firms' technology is subject to idiosyncratic and common shocks. The value of future technology rents drive stock market valuation. We study how the arrival of new information about future technological developments affect each firm's stream of future profit, the rate on return on physical capital, and the value of equity. We show that good news about future technology of a specific firm or industry will lift the price of shares of the specific firms, but that good news about future aggregate productivity will raise the discount rate, leaving the price of shares unchanged. On the other hand, good news about future aggregate profit margins will lift the price of shares.
\end{abstract}

KEYWORDS: Equity, Heterogeneous (non-representative) firms, Monopolistic Competition, Real Business Cycle (RBC), Stock Market.

JEL Classification: E25, E32, G12.

Corresponding author:

Prof. Gabriel Talmain (e-mail: g.talmain@gla.ac.uk)

Department of Economics

University of Glasgow

Glasgow

G12 8RT 


\section{Introduction}

The question of the pricing of assets, especially of shares of stocks, has long been of immense theoretical and practical interest. Early modern treatment can be found in Arrow (1953) and in Radner (1972). Ever since, a vast body of literature has develop in many directions. However, to our knowledge, all recent papers in the area make assumptions that yield an exogenous the stream of dividends and/or an exogenous rate of interest that can be used to calculate present values. For instance, the interest rate in Greenwood and Jovanovic (1999) is determined endogenously, but the dividends are exogenous. In Zeira (1999), dividends are determined endogenously, but the interest rate is exogenous (either by fiat or by the small-open economy assumption) and deterministic. Indeed, there are many papers in the area well deserving attention, but a general survey of the literature is well beyond the scope of this paper. Extending economic analysis to a framework in which interest rates, dividends and share prices are all determined simultaneously and endogenously would be highly desirable. Macroeconomic factors, such as the unexpected arrival of profitable investment opportunities due, say, to technology breakthroughs, or such as changes in the propensity to save, are likely to affect all of the previous variable simultaneously. Since these variables are all strongly related through some type of arbitrage condition, the effect of, or even direction imparted by these interactions is by no mean obvious.

For instance, the recent almost unprecedented rise of the stock market in the US and other industrial countries has generated considerable interest, hope and, in some, a sense of foreboding. Some very influential high-ranking members of the business and finance community have issued words of caution, citing the precedent of the Nikkei stock bubble of the eighty's, or even more dramatic past events. On the other hand, some financial analysts have propagated, through the popular financial press, a much more optimistic view. They have argued that the rapid maturing of a considerable range of new technologies has created the prospect for unfathomable new wealth, the "new economy". Hence, the recent rise in the stock market is simply an expression of the expected future effects of these technological developments. Can the expectation of new technology by itself explain dramatic price movements in the stock market? Certainly, at the level of an individual firm, an expected technology breakthrough will make a firm more valuable than its competitors and its share price will express the new situation. But would the same effect hold at the aggregate level? An expected increase in aggregate productivity ceteris paribus would tend to make shares of stock more valuable, but this expected change in the future will also drive up interest rates, putting in doubt the magnitude, or even the direction, of the net effect.

Although highly desirable, building a model to determine simultaneously stock market values and interest rate raises difficult technical challenges which, in our opinion, explains the lack of progress in this direction. A meaningful model of 
the stock market should include some non-trivial form of heterogeneity among firms and tackle the presence of risk to the investors, including preferably both aggregate and idiosyncratic risk. Technology shocks will affect both the value of the shares of stock and the price the firm charges for its good, its market share and its hiring of resources (labour and capital). In turn, owners of resources, e.g. workers, and will react as consumers to these price changes, but consumers will also react to capital gains and losses in the stock market by changing their savings rate. In addition, consumers, in their role as investors in the financial markets, have to evaluate whether the price of each particular stock is "right". The latter point is especially non-trivial when one starts addressing the inherent incompleteness of the market structure.

\subsection{Outline of the model}

This paper endeavours to address all of these issues. The baseline model is a real business cycle $(R B C)$ model with a fixed number of heterogeneous monopolisticaly competitive firms à la Dixit-Stiglitz and identical representative infinitely lived agents à la Ramsey. This model first appeared in Abadir and Talmain (1998). Each monopoly firm produces a non-storable differentiated good which is used as an intermediate product in the production of an homogenous final good. This final good can be used for either consumption in the current period or for physical capital formation in the next period. As this industry operates under constant returns and is competitive, it plays no part in the stock market. It does, however, generate a derived demand for the differentiated products. Intermediate-product firms hire, in each period and in a competitive market, physical capital and labour to produce their product. Because these firms are monopolies, they generate profits even after paying the rental and the wage bills. In the tradition of the RBC literature, the firms' technology is subject to random shocks in each period, and the originality in our model is to let these shocks be firm-specific, hence the heterogeneity. It is optimal for firms with higher productivity to sell at a lower price in order to capture a larger market share. Clearly, these firms will also earned higher profits, hence these profits are akin to technology-based rent. The (endogenous and stochastic) stream of future profits, immediately distributed as dividend to the equity owners, creates value for the ownership of a monopoly firm, and we assume that firm ownership is traded in a stock market as shares of stocks. As each firm is associated with a unique stream of future profits, and, as each period adds information on the long-term prospects of a firm, each firm will have its own value, and this value will fluctuate over time with the arrival of good news and bad news about its technology. Financial investors have the choice between two types of investments, all risky: physical capital, whose return is rental, and equity investment, whose return is dividend plus capital gains (or losses). The representative agents hold the initial stock of physical capital and all shares of stocks; they inelastically supply 
labour. Hence, they receive all income in each period (there is no government in this closed-economy). Given the stream of future wages and returns on the various assets, agents must simultaneously decide on their consumption/savings programme and on their portfolio allocation.

\subsection{A simplifying remark}

The reader will have noticed that nothing was said about the existence of a complete system of Arrow's state-contingent securities. It has been noted, see Magill and Quinzii (section 33, pp 431-439, 1996) ${ }^{1}$, that incomplete asset markets often lead to generic indeterminacy of the set of equilibria, i.e. not only is equilibrium not unique but it is not locally unique: there is a whole interval [dimension 1], or a whole disk [dimension 2], or a whole ball [dimension 3] .... of equilibria! The assumption of a representative consumer help us out of this predicament. It has been shown, Talmain (1999), that the equilibrium that prevails under a system of complete asset markets can also be supported when such securities are not present, providing there are $M-1$ nominal assets, where $M$ is the number of types of agents in the economy. Since $M=1$ in our case, no nominal asset is needed and the asset markets are essentially complete: introducing a system of Arrow's securities will not change the real equilibrium; it is the real equilibrium that will price these securities (revealing their shadow price).$^{2}$

\subsection{Results}

Using the fact that asset markets are essentially complete, we derive the fundamental path of the economy in our model. This path is characterised by a constant savings rate. Other equilibrium paths might exist, but there will be associated with a savings rate which tends to 1 , almost surely, a very counterfactual property. Furthermore, these paths are associated with capital stocks that are so high (because the savings rate is close to 1) and interest rates that are so low

\footnotetext{
${ }^{1}$ As pointed out in Magill and Quinzii, indeterminacy of the real allocation would not arise if all securities were real contracts. In our setting, shares of stock include a nominal component in the form of possible capital gains and losses, hence indeterminacy of the real allocation cannot be ruled out.

${ }^{2}$ The intuition for this result is very simple in this case. It has often been pointed out that the system of state-contingent securities can be thought of as insurance. Consider first the situation in the absence of a system of Arrow's securities. The representative agent selects the best allocation available, which presumable incoporates some risk. Suppose the system of Arrow's securities is introduced. The agent would like to use these securities to trade away the uncertainty of his allocation. However, there is no one else in the economy to trade with. Suppose the initial price of one of these Arrow's securities was initially "low". All agents would want to buy that security, bidding up its price. The bidding up will stop when the price at which the security is trading corresponds to its shadow price, determined from the preferences (more precisely, from the tangent hyperplan to the indifference surface) of the representative consumer at its initial allocation.
} 
(since interest rate is negatively related with capital stock) that the sum defining present values do not converge!

In our model, we show that, in a rational expectation equilibrium in which the data generating process validates the expectations of the agents, the current value of the market portfolio depends on the rate of time discount preferences, on the rate of profits in the economy and on current output. In other words, no advances in technologies in the future, whether the agents always anticipated it or received unexpected news of such development, can explain a sudden increase in the value of the stock market in the absence of a corresponding increase in current output. The intuition is as follows. Good news about future aggregate technology implies that the rate of return on physical capital will be high in the future. The price of physical capital is equal to the price of the consumption good as they are perfect substitutes, hence the good news cannot change the value of current capital, i.e. the increase in the rate of discount is just enough to cancelout the increase in productivity of capital. We know now that future profits are discounted at a higher rate, but the good news means that these profits will be higher, so the effect is still ambiguous at this stage. Suppose that the arrival of good news were to cause an increase in the value of the stock market. This increased wealth will cause a contemporaneous increase in consumption. Current aggregate output is not affected because the better technology has not arrived yet. Hence, in the absence of a government/foreign sector, investment must decrease to accommodate the rise in aggregate consumption, but this cannot occur because the price of capital is still the same as the price of consumption.

On the other hand, an increase in the future profit margin, even in the aggregate, will immediately lift the current value of shares.

Extension to open economy: if the stock market in the US goes up and the preceding applies, then the overall stock market is constant and the stock market oversee must go down.

\section{Framework}

\subsection{Basic framework}

We are considering an infinite-horizon period economy starting at time $t=0$ which includes $L$ identical representative consumers à la Ramsey and $N$ monopolistically competitive firms whose shares of stocks are traded on the stock market.

On the production side, there are three sectors: the final good sector, which is perfectly competitive, the leasing sector which owns the stock of physical capital in the economy and rents it out to monopoly firms, this sector is perfectly competitive, and the intermediate good sector, which includes a fixed number $N$ of monopolistically competitive firms each producing a non-storable differen- 
tiated product. The final good sector uses intermediate goods as its only input and the intermediate product sector uses labour and capital as its inputs. The intermediate inputs are used solely by the final good industry and the final good is either used for consumption in the current period or stored as capital for the next period. We assume $100 \%$ depreciation of capital, i.e. output produced at time $t$, that is not used for consumption in that period, becomes capital in the next period and is destroyed in the production process (at an equilibrium, the rental of capital will be such as to make capital formation a viable proposition).

On the consumer side, we adopt a infinitely lived representative consumer model $\grave{a}$ la Ramsey. ${ }^{3}$ The $L$ representative consumers inelastically supply $L$ units of labour per period, owns all shares of stocks, all capital, uses its income in each period to consume and to accumulate wealth in the form of capital formation and (from the point of view of the individual) investment in shares of stocks. ${ }^{4}$

\section{$2.2 \quad$ Aggregation and derived demand}

\subsubsection{Production}

Final good industry A final good industry, operating under perfect competition, uses this specialised inputs to produce a final good according to the standard CES aggregation function, see for instance Bénassy (1996),

$$
Y_{t} \equiv\left[\sum_{n=1}^{N} u_{n, t}^{1-\rho} q_{n, t}^{\rho}\right]^{1 / \rho}, \quad \rho \in(0,1), \quad \sum_{n=1}^{N} u_{n, t}=1,
$$

where $Y_{t}$ is the aggregate output of the final good industry, $q_{n, t}$ is the output of firm $n$, the $u_{n, t}$ are exogenous coefficients that will capture the share of aggregate demand that goes to each firm $n$ at time $t^{5}$ and $(1 /(1-\rho))$ is the elasticity of substitution betweeen two products. The parameter $\rho$ is also a measure of the degree of competitveness of the economy, with competitiveness increasing with $\rho$, when $\rho \rightarrow 1$ this economy tends towards perfect competition.

The aggregate output $Y_{t}$ can be used either for consumption or for investment purposes. Investment in period $t$ increases the capital stock of period $t+1$, i.e. with a one period lag. In order to be able to derive a closed form solution for the

\footnotetext{
${ }^{3}$ We think of this representative agent as a paradigm for $L$ dynastic agents with the same preferences and the same initial endowment, with $L$ large enough to justify perfectly competitive behaviour. Since all agents face the same problem, they all behave in the same way and their aggregate behaviour is simply a multiple of each individual (competitive) behaviour.

${ }^{4}$ It is clear that the aggregate excess demand for shares must be 0 in every period.

${ }^{5}$ We shall see that, if all firms employ the same technology (which will be characterised latter by $\theta_{n, t}=\theta_{t}$ ), they will all optimise by charging the same price. Under this price structure, the equilibrium output of firm $n$ will be

$$
q_{n, t}=u_{n, t} Y_{t}
$$
}

where $Y_{t}$ is the output of final good: the output of the firm is proportional to $u_{n, t}$. 
intertemporal equilibrium of our economy, we need to assume, as in Devereux et al. $(1993,1996)$, a $100 \%$ depreciation rate on capital. Hence, the stock of capital in period $t+1$ is equal to the investment of period $t$.

Intermediate product industry The productive sector of the economy is composed of $N$ infinitely-lived monopolistically competitive firms. We assume that good $n$ is produce according to a standard Cobb-Douglas production function which takes capital and labour as inputs

$$
q_{n, t}=\theta_{n, t} K_{n, t}^{\gamma} L_{n, t}^{1-\gamma}, \quad \gamma \in(0,1)
$$

where, for firm $n, \theta_{n, t}$ is the technical efficiency and $K_{n, t}, L_{n, t}$ are the inputs of labour and capital used up by the firm. Each firm $n$ is characterised by its own technology level $\theta_{n, t}$. Individual productivities follow some autoregressive process to be specified latter. An example of such a process would be a geometric AR(1) process

$$
\log \theta_{n, t}=\alpha_{n} \log \theta_{n, t-1}+\epsilon_{n, t}
$$

where the shocks $\epsilon_{n, t}$ can incorporate a firm-specific component in addition to the usual economy-wide component, and can be made to have a non-zero mean. These monopoly firms will make positive profits in each period. These profits are assumed to be immediately distributed as dividends to the share holders.

\subsubsection{Allocation}

Efficient allocation Let us consider the problem of production from the point of view of a Central Planner before addressing the question of the market allocation. At time $t$, the aggregate resources of the economy are either predetermined, the aggregate capital $K_{t}$, or exogenously given, the aggregate labour $L$, or a combination of both, the productive structure of the economy characterised by the number of monopoly firms $N$ and their productivity $\theta_{n, t} \cdot{ }^{6}$ There exist an allocation of these resources across firms that will maximise final output $Y_{t}$

$$
Y_{t}=\theta_{t} k_{t}^{\gamma} L_{t}
$$

where $\theta_{t}$ is aggregate productivity and $k_{t}$ is the capital/labour ratio of the economy

$$
\begin{aligned}
\theta_{t}^{\nu} & \equiv \sum_{n=1}^{N} u_{n, t} \theta_{n, t}^{\nu}, \quad \nu \equiv \frac{\rho}{1-\rho} \\
k_{t} & \equiv \frac{K_{t}}{L_{t}}
\end{aligned}
$$

\footnotetext{
${ }^{6}$ Strictly speaking, one should also add the technology of the final good industry, which is unchanging over time in our framework.
} 
Since the agents only care for the final good, either for consumption or investment, this allocation would be the solution of the Central Planner problem. Defining $y_{t}$ as the output per capita

$$
y_{t} \equiv \frac{Y_{t}}{L},
$$

the efficient allocation of factors will yield the following relationship between resources and aggregate output (in per-capita terms)

$$
y_{t}=\theta_{t} k_{t}^{\gamma} .
$$

This efficient allocation is characterised, for firm $n$, by output, employment and physical capital allocation (all in per-capita terms)

$$
\begin{aligned}
q_{n, t} & =u_{n, t}\left[\frac{\theta_{n, t}}{\theta_{t}}\right]^{1 /(1-\rho)} y_{t}, \\
l_{n, t} & =u_{n, t}\left[\frac{\theta_{n, t}}{\theta_{t}}\right]^{\nu}, \\
k_{n, t} & =u_{n, t}\left[\frac{\theta_{n, t}}{\theta_{t}}\right]^{\nu} k_{t} .
\end{aligned}
$$

As it turns out, the market allocation mechanism will yield this technically efficient allocation. This outcome is reminiscent of the first theorem of welfare economics, although the environment here is different.

Market allocation The market allocation will be supported by characterised by the following prices and quantities.

Prices of output Let $p_{t}$ be the price of the final good, $\tilde{p}_{n, t}\left[\right.$ resp. $\left.p_{n, t}\right]$ be the nominal [resp. relative] price of intermediate product $n$

$$
p_{n, t} \equiv \frac{\tilde{p}_{n, t}}{p_{t}} .
$$

The relative price of a product is inversely proportional to the productivity of the firm, i.e. more productive firms charge a lower price (and generate more demand for their product)

$$
p_{n, t}=\frac{\theta_{t}}{\theta_{n, t}} .
$$

Factor prices and pure rent Let $\tilde{w}_{t}$ and $\tilde{l}_{t}^{k}$ and [resp. $w_{t}$ and $\left.i_{t}^{k}\right]$ be the nominal [resp. real] wage rate and rental rate, respectively

$$
w_{t}=\frac{\widetilde{w}_{t}}{p_{t}} \quad \text { and } \quad i_{t}^{k}=\frac{\widetilde{i}_{t}^{k}}{p_{t}} .
$$


Then the real wage rate is proportional to output and it is an increasing function of the capital/labour ratio. The real rental rate is a decreasing function of the capital/labour ratio.

$$
w_{t}=(1-\gamma) \rho y_{t} \quad \text { and } \quad i_{t}^{k}=\frac{\gamma \rho y_{t}}{k_{t}} .
$$

Let the nominal [resp. real] profits of firm $n$ be $\tilde{\Pi}_{t}^{n}\left[\right.$ resp. $\left.\Pi_{t}^{n}\right]$. The real profit of firm $n$ is proportional to output $Y_{t}$, to the weight of the firm in demand $u_{n, t}$, and is increasing with the relative technical efficiency of the firm $\varphi_{n, t}$

$$
\begin{aligned}
\Pi_{t}^{n} & \equiv \frac{\tilde{\Pi}_{t}^{n}}{p_{t}}=u_{n, t} \varphi_{n, t}^{\nu}(1-\rho) Y_{t}, \\
\text { where } \varphi_{n, t} & \equiv \frac{\theta_{n, t}}{\theta_{t}} .
\end{aligned}
$$

These profits represent pure rent: they would disappear under free entry.

Share of the factors Let $\widetilde{\bar{\Pi}}_{t}\left[\right.$ resp. $\left.\bar{\Pi}_{t}\right]$ be the aggregate nominal [resp. real] monopoly profits

$$
\widetilde{\bar{\Pi}}_{t}=\sum_{n=1}^{N} \tilde{\Pi}_{t}^{n} \text {, and } \bar{\Pi}_{t} \equiv \frac{\widetilde{\bar{\Pi}}_{t}}{p_{t}}=(1-\rho) Y_{t} .
$$

Define $\bar{\pi}_{t}$ as the real profit per capita in the economy

$$
\bar{\pi}_{t}=\frac{\bar{\Pi}_{t}}{L}
$$

Output per capita $y_{t}$ is distributed among the factors as follows: the share of labour, capital and profit are respectively

$$
\begin{aligned}
\frac{w_{t}}{y_{t}} & =(1-\gamma) \rho, \\
\frac{k_{t} i_{t}^{k}}{y_{t}} & =\gamma \rho, \\
\frac{\bar{\pi}_{t}}{y_{t}} & =(1-\rho) .
\end{aligned}
$$

A share $\rho=(\nu /(1+\nu))$ of output is distributed as payments to either labour or capital

$$
w_{t}+k_{t} i_{t}^{k}=\rho y_{t} .
$$

The balance $(1-\rho)=(1 /(1+\nu))$ goes to profits. 
Return on assets There are $N+1$ assets in the economy, only one of which, physical capital, allows for accumulation of wealth at the aggregate level. The value of the other $N$ assets, shares of stocks in the monopoly firms, follow a stochastic path which is driven by technology considerations (for the fundamental path) and expectations (for other paths) which are independent (at the aggregate level) of the agents' actions. The real return on holding physical capital from the end of period $t$ to the beginning period $t+1$ is the real rental $i_{t+1}^{k}$ only since the rate of depreciation of capital is $100 \%$. Let $\tilde{V}_{t}^{n}$ be the ex-dividend nominal value of firm $n$ at the end of period $t$. The firm value at the beginning of the period is the with-dividend value $V_{t}^{n}+\Pi_{t}^{n}$; this value is known at the beginning of the period as all uncertainty for the period has already been realised. The ex-dividend real value of the firm is

$$
V_{t}^{n}=\frac{\tilde{V}_{t}^{n}}{p_{t}}
$$

The nominal return $\tilde{\imath}_{t+1}^{n}$ on holding shares of firm $n$ from $t$ to $t+1$ is

$$
\tilde{\imath}_{t+1}^{n}=\frac{\tilde{V}_{t+1}^{n}+\tilde{\Pi}_{t+1}^{n}}{\tilde{V}_{t}^{n}}
$$

and the real return $i_{t+1}^{n}$ is

$$
i_{t+1}^{n}=\frac{p_{t}}{p_{t+1}} \tilde{\imath}_{t+1}^{n}=\frac{V_{t+1}^{n}+\Pi_{t+1}^{n}}{V_{t}^{n}} .
$$

Let the real aggregate market portfolio $\bar{V}_{t}$ of shares be defined as the combined value of all shares of stocks, and let $\bar{v}_{t}$ be the (per capita) market portfolio and $v_{t}^{n}$ be the per capita capitalisation value of firm $n$

$$
\bar{V}_{t} \equiv \sum_{n=1}^{N} V_{t}^{n}, \quad \bar{v}_{t} \equiv \frac{\bar{V}_{t}}{L}, \quad v_{t}^{n} \equiv \frac{V_{t}^{n}}{L} .
$$

The real return on the market portfolio $\bar{l}_{t+1}$ is defined as the real return on holding shares in firm $n$ in proportion to its market capitalisation

$$
\bar{\imath}_{t+1} \equiv \sum_{n=1}^{N} i_{t+1}^{n} \frac{V_{t}^{n}}{\bar{V}_{t}} \Longrightarrow \bar{\imath}_{t+1} \bar{v}_{t}=\sum_{n=1}^{N} i_{t+1}^{n} v_{t}^{n} .
$$

\subsubsection{Consumer optimum}

Opportunity set There are $L$ identical representative agents in the economy. Consider the representative agent $l$. He supplies inelastically one unit of labour per period. He also starts in period 0 with an initial endowment of capital 
$k_{0}^{l}=k_{0} \equiv K_{0} / L$ and with an equal share of equity in each firm. Hence, the real value of his initial stocks holding is

$$
\bar{v}_{0}^{l}=\bar{v}_{0} \equiv \frac{\bar{V}_{0}}{L}=\frac{\sum_{n=1}^{N} V_{0}^{n}}{L} .
$$

National income National income is the sum of earned and unearned income. In per capita term, earned income is the wage rate $w_{t}$. Unearned income is composed of rental income $i_{t}^{k} k_{t}$ and equity income, which includes profit income (rent) $\bar{\pi}_{t}$ and capital gains $\Delta v_{t} \equiv\left(\bar{v}_{t}-\bar{v}_{t-1}\right)$. Hence, using the fact that factors' income plus rent adds up to aggregate output $y_{t}$, national income per capita, which is also the income $y_{t}^{l}$ of agent $l$, is

$$
y_{t}^{l}=n i_{t}=y_{t}+\Delta v_{t}
$$

Dynamic budget constraint Given the holdings of capital $k_{t}^{l}=k_{t}$ and of real value $v_{t-1}^{l, n}=v_{t-1}^{n}$ of share holdings in each firm $n$ at the end of period $t-1$, the consumer real resources at the beginning of period $t$ are

$$
i_{t}^{k} k_{t}^{l}+\sum_{n=1}^{N} i_{t}^{n} v_{t-1}^{l, n}+w_{t}
$$

he must allocate his resources between consumption $c_{t}^{l}$, and acquisition of assets for next period, either as capital for next period $k_{t+1}^{l}$ or as shares in monopoly firms $v_{t}^{l, n}$. The dynamic budget constraint is therefore

$$
i_{t}^{k} k_{t}^{l}+\sum_{n=1}^{N} i_{t}^{n} v_{t-1}^{l, n}+w_{t}=c_{t}^{l}+k_{t+1}^{l}+\sum_{n=1}^{N} v_{t}^{l, n} .
$$

Let us define $a_{t}^{l}$ as the real value of the financial wealth of the consumer at the end of period $t$

$$
a_{t}^{l} \equiv k_{t+1}^{l}+\sum_{n=1}^{N} v_{t}^{l, n}=k_{t+1}^{l}+\bar{v}_{t}^{l}
$$

and let the real return on aggregate financial wealth of consumer $l, \overline{\bar{i}}_{t}^{l}$, be defined as

$$
\overline{\bar{i}}_{t}^{l} \equiv \frac{i_{t}^{k} k_{t}^{l}+\sum_{n=1}^{N} i_{t}^{n} v_{t-1}^{l, n}}{a_{t-1}^{l}} ;
$$

return which is determined by the consumer through his (endogenous) portfolio allocation. The dynamic budget constraint can be written in the usual form as

$$
a_{t}^{l}=\overline{\bar{i}}_{t}^{l} a_{t-1}^{l}+w_{t}-c_{t}^{l}
$$


Intertemporal budget constraint The opportunity set of the consumer can also been investigated from his initial position at time 0 . Consider a particular realisation of path of consumption $\mathbf{c}^{l} \equiv\left\{c_{t}^{l}\right\}_{t=0}^{\infty}$ and real wage income $\mathbf{w} \equiv$ $\left\{w_{t}\right\}_{t=0}^{\infty}$. Of course, such realisation is only known "at the end of time". Let us define a discount factor between period 0 and period $t$ based on the rate of return on physical capital as ${ }^{7}$

$$
d_{t} \equiv \frac{1}{\prod_{\tau=1}^{t} i_{t}^{k}}
$$

Assuming that all the following sums do converge, we define $P V_{0}(\mathbf{c})$ and $P V_{0}(\mathbf{w})$ as the present values of the stream of consumption and wage income, respectively

$$
P V_{0}\left(\mathbf{c}^{l}\right)=\sum_{t=0}^{\infty} d_{t} c_{t}^{l}, \quad P V_{0}(\mathbf{w})=\sum_{t=0}^{\infty} d_{t} w_{t}
$$

Notionally, these two present values are stochastic variables (in a continuoustime context, they would be Itô's integrals). However, we will see that these sums turn out to be deterministic variables on the fundamental path. On every realisation of uncertainty, the consumer consumption/savings programme must satisfy (ex-post)

$$
P V_{0}\left(\mathbf{c}^{l}\right)=\bar{v}_{0}^{l}+\bar{\pi}_{0}^{l}+i_{0}^{k} k_{0}^{l}+P V_{0}(\mathbf{w}) \Longrightarrow P V_{0}(\mathbf{c})=\bar{v}_{0}+\bar{\pi}_{0}+i_{0}^{k} k_{0}+P V_{0}(\mathbf{w})
$$

the last equality holding due to the representative agent assumption.

Optimization The problem of the consumer is to maximize his expected discounted utility, given his expectations, subject to his budget constraint

$$
\max _{\substack{c_{t}^{l}, \bar{i}_{t}^{l}\\}} \mathcal{E}_{0}\left[\sum_{t=0}^{\infty} \delta^{t} \log c_{t}^{l} \mid \mathcal{I}_{0}^{l}\right] \text {, s.t. } a_{t}^{l}=\overline{\bar{i}}_{t}^{l} a_{t-1}^{l}+w_{t}-c_{t}^{l} \text { and } k_{0}^{l}, \bar{v}_{0}^{l} \text { given, }
$$

where $\delta$ is the (subjective) discount factor and $\mathcal{E}_{t}\left[\cdot \mid \mathcal{I}_{t}^{l}\right]$ denotes the expectation operator with respect to the information available at time $t$ and his expectations $\mathcal{I}_{t}^{l}$ at time $t$ about the future.

The consumer must devise both a consumption/savings programme to smooth and to insure his consumption over time, and a portfolio diversification strategy that will exhaust all subjective arbitrage opportunities. Both of these requirements are expressed in the Euler equation which states that, for every asset $x$

\footnotetext{
${ }^{7}$ Alternative definitions of a discount rate can be given using for instance the (endogenous) aggregate return $\left\{\overline{\bar{i}}_{t}\right\}_{t=1}^{\infty}$ or even the return on a specific share as the underlying interest rate. However, the Euler equations will insure that all of these definitions would produce the same valuation of future consumption from the point of view of the consumer.
} 
available to the consumer (i.e. physical capital and the equity in monopoly firms) with real return $i_{t+1}^{x}$, the consumer will adjust his portfolio/savings such that

$$
\frac{1}{c_{t}^{l}}=\mathcal{E}_{t}\left[\frac{\delta i_{t+1}^{x}}{c_{t+1}^{l}} \mid \mathcal{I}_{t}^{l}\right]
$$

Hence, the consumer must devise a consumption programme that $(i)$ is a Euler path - it satisfies (9), and (iia) either satisfies the intertemporal budget constraint (8) if the infinite sums that define the present value converge, or $(i i b)$ satisfies the dynamic budget constraint (7) plus some borrowing constraint such as a no-Ponzi-Game constraint.

\section{Dynamic Equilibrium}

\subsection{Market clearing}

In each period $t$, there are $N+1$ commodity markets: the market for final good and the $N$ markets for the differentiated products. From our earlier discussion on the efficient nature of market allocation, it is clear that the markets for intermediate products will clear as soon as the market for the final good clears. The supply of final good, which we calculated in (2), is given by the efficient use of the resources of the economy. There are two sources of demand for the final good (all in per capita terms): consumption $c_{t}$, where $\forall l, c_{t}^{l}=c_{t}$ by the representative consumer assumption, and investment in physical capital. Since capital depreciation is $100 \%$ in each period, investment in period $t$ is equal to the capital stock of the next period $k_{t+1}$. Hence, the market clearing condition for the final good market is

$$
c_{t}+k_{t+1}=\theta_{t} k_{t}^{\gamma} .
$$

Note that this condition implies that the capital stock at time $t+1$ is predetermined.

The additional markets to consider are the market for physical capital and the $N$ equity markets for the ownership of the $N$ firms. Assuming the market for the final good clears in period $t+1$, the demand for physical investment in period $t$ is $k_{t+1}$. Let $s_{t}$ be the rate of saving out of aggregate output, so that per capita aggregate savings are $s_{t} y_{t}$. Aggregate savings have to be equal to capital accumulation as the firm ownership is not an outlet for aggregate accumulation. Hence, equilibrium in the physical capital market requires

$$
s_{t} y_{t}=k_{t+1} \text {. }
$$

Together with the final goods market clearing equation, this relationship implies

$$
c_{t}=\left(1-s_{t}\right) y_{t} \text {. }
$$

Finally, the monopoly firms will be valued by the Euler equation which will ensure that equity holding in every firm is a competitive proposition. 


\subsubsection{Implication for the consumption/savings path}

Let us consider one realisation of the path of the economy; in particular the path of savings $\left\{s_{t}\right\}_{t=0}^{\infty}$ is determined. First, let us note that, from (3), the value of output per capita discounted by the rental is predetermined (it is independent of the realisation of uncertainty at time $t+1$ )

$$
\frac{y_{t+1}}{i_{t+1}^{k}}=\frac{1}{\gamma \rho} k_{t+1}=\frac{1}{\gamma \rho} s_{t} y_{t}=\delta \frac{s_{t}}{s^{*}} y_{t}
$$

where $s^{*}$ (which will turn out to be the constant saving rate of the fundamental path) is defined as

$$
s^{*} \equiv \gamma \delta \rho
$$

Hence

$$
\begin{aligned}
P V_{0}\left(y_{t}\right) & =d_{t} y_{t}=\delta \frac{s_{t-1}}{s^{*}} d_{t-1} y_{t-1} \Longrightarrow P V_{0}\left(y_{t}\right)=\delta^{t}\left(\prod_{\tau=0}^{t-1} \frac{s_{\tau}}{s^{*}}\right) y_{0} \\
\Longrightarrow & P V_{0}(\mathbf{y})=y_{0} \sum_{t=0}^{\infty}\left[\delta^{t}\left(\prod_{\tau=0}^{t-1} \frac{s_{\tau}}{s^{*}}\right)\right]
\end{aligned}
$$

the last equality holding only if the present value of the stream of output exists, i.e. if

$$
\lim _{T \longrightarrow \infty} \sum_{t=0}^{T}\left[\delta^{t}\left(\prod_{\tau=0}^{t-1} \frac{s_{\tau}}{s^{*}}\right)\right] \text { exists. }
$$

Notice that this last condition holds on the fundamental path $s_{t}=s^{*}$, but will not hold if $\lim _{t \longrightarrow \infty} s_{t}=1$ as

$$
\begin{aligned}
\forall \epsilon \quad & \quad(0,1-\gamma \rho), \exists T_{\epsilon}, \forall t \geq T_{\epsilon}, s_{t}>1-\epsilon \\
\Longrightarrow & \delta^{t}\left(\prod_{\tau=0}^{t-1} \frac{s_{\tau}}{s^{*}}\right) \propto \delta^{t-T_{\epsilon}}\left(\prod_{\tau=T_{\epsilon}}^{t-1} \frac{1-\epsilon}{s^{*}}\right)=\left(\frac{1-\epsilon}{\gamma \rho}\right)^{t-T_{\epsilon}} \longrightarrow \infty
\end{aligned}
$$

This implies that

$$
P V_{0}\left(c_{t}\right)=P V_{0}\left(y_{t}-s_{t} y_{t}\right)=P V_{0}\left(y_{t}\right)-\frac{s^{*}}{\delta} P V_{0}\left(y_{t+1}\right) .
$$

Hence

$$
P V_{0}(\mathbf{c})=\left(1-\frac{s^{*}}{\delta}\right) P V_{0}(\mathbf{y})+\frac{s^{*}}{\delta} y_{0} .
$$

Since, from the factor price equation (3), we have

$$
P V_{0}(\mathbf{w})=(1-\gamma) \rho P V_{0}(\mathbf{y}),
$$


the intertemporal budget constraint (8), and the fact that the per-capita consumption, equity holdings, $\mathbf{\square}$ must be equal to agent's $l$ consumption, $\mathbf{\square}$ implies

$$
\bar{v}_{0}=(1-\rho)\left[P V_{0}(\mathbf{y})-y_{0}\right] .
$$

Two remarks:

1. Calculating $P V_{0}(\overline{\boldsymbol{\pi}})$, the value of the stream of profits starting at time $t=1$ (since the current profits have already been distributed), we find

$$
P V_{0}(\overline{\boldsymbol{\pi}})=(1-\rho)\left[P V_{0}(\mathbf{y})-y_{0}\right]=\bar{v}_{0},
$$

hence the value of the market portfolio coincides with the fundamental value of that portfolio.

2. Since the previous equality must hold for every path and that both $\bar{v}_{0}$ and $y_{0}$ are fixed at time $t=0$, this implies that the present value of income must be path-independent: the consumer adapts his consumption so that its present value does not depend on the realisation of uncertainty.

\subsection{Rational expectation path}

We are going to turn our attention at the equilibrium path of the economy when agents hold rational expectations and that these expectations are validated by the data generating process which drives the technology shocks of the economy.

\subsubsection{Fundamental path of capital accumulation}

Characterisation of the Euler paths Since the Euler equation (9) must hold for the rental given by (3), we have

$$
\frac{1}{c_{t}^{l}}=\mathcal{E}_{t}\left[\frac{\delta i_{t+1}^{k}}{c_{t+1}^{l}}\right]=\mathcal{E}_{t}\left[\frac{s^{*} y_{t+1}}{k_{t+1} c_{t+1}^{l}}\right] .
$$

Let us define the auxiliary variable $s_{t}^{l}$, which will turn out to be the savings rate of agent $l$ :

$$
s_{t}^{l} \equiv \frac{y_{t}-c_{t}^{l}}{y_{t}} .
$$

Substituting for $c_{t}^{l}$ and for $k_{t+1}$ from (10) allows us to write the Euler equation for the rental as

$$
\frac{1}{1-s_{t}^{l}}=\frac{s^{*}}{s_{t}} \mathcal{E}_{t}\left[\frac{1}{1-s_{t+1}^{l}}\right] .
$$


Euler paths and equilibrium Any consumption programme can be written, as we have previously done, as $\mathbf{s}^{l} \equiv\left\{s_{t}^{l}\right\}_{t=0}^{\infty}$ with

$$
c_{t}^{l}\left(\mathbf{s}^{l}\right)=\left(1-s_{t}^{l}\right) y_{t}
$$

however, for an arbitrary $\mathbf{s}^{l}$, this programme may not be feasible (i.e. it can violate the consumer's budget constraint) and it may not be an Euler programme, i.e. it may not satisfy (12). In addition, clearance of the physical capital requires

$$
\mathbf{s}^{l}=\mathbf{s} \text {, i.e. } \forall t \geq 0, \quad s_{t}^{l}=s_{t} ;
$$

as the demand for funds to invest in physical capital is, in per-capita terms, $\left\{s_{t} y_{t}\right\}_{t=0}^{\infty}$ and the supply of such funds is $\left\{s_{t}^{l} y_{t}\right\}_{t=0}^{\infty}$. Only Euler consumption programmes are candidates for an (interior) optimum. Consider the set (as yet unknown) $\mathcal{S}^{l}$ of all feasible Euler consumption programmes. The optimal consumption/saving programme of the consumer corresponds to solving

$$
\max _{\mathbf{s}^{l} \in \mathcal{S}^{l}} \mathcal{E}_{0}\left[\sum_{t=0}^{\infty} \delta^{t} \log \left(1-s_{t}^{l}\right) y_{t}\right]=\max _{\mathbf{s}^{l} \in \mathcal{S}^{l}} \mathcal{E}_{0}\left[\sum_{t=0}^{\infty} \delta^{t} \log \left(1-s_{t}^{l}\right)\right]+\text { cste. }
$$

The consumer must solve this problem taking $\mathbf{s}$ and $\mathbf{y}$ as given. The log specification causes the output path $\mathbf{y}$ to nicely drop out, but the presence of aggregate savings s makes this problem non-trivial. However, we can show, with relative ease, that the deterministic aggregate savings rate $\mathbf{s}^{*} \equiv\left\{s_{t}=s^{*}\right\}_{t=0}^{\infty}$ is in fact an equilibrium of the economy. Traditionally, this path has been labelled the fundamental path of the economy.

Fundamental path Let us assume that the aggregate savings rate follows the deterministic path $\mathbf{s}^{*} \equiv\left\{s_{t}=s^{*}\right\}_{t=0}^{\infty}$. It is clear that the consumption programme $\forall t \geq 0, \quad s_{t}^{l}=s^{*}$ is feasible and would clear the market for physical capital. However, to show that this path is indeed an equilibrium path, we need to demonstrate further that the optimal consumption programme of the consumer $l$ is

$$
\forall t \geq 0, \quad s_{t}^{l}=s^{*} .
$$

Proof. The Euler condition becomes

$$
\frac{1}{1-s_{t}^{l}}=\mathcal{E}_{t}\left[\frac{1}{1-s_{t+1}^{l}}\right]
$$

Let $\mathcal{S}_{1}^{l}$ be the set of all savings that satisfy this property and note that the marginal utility of consumption is a martingale. The present value of output in the previous period is deterministic:

$$
\frac{y_{t+1}}{i_{t+1}^{k}}=\delta y_{t}
$$


Hence, the present value at time 0 of output per capita $y_{t}$, which is a priori a random variable, is path-independent:

$$
P V_{0}\left(y_{t}\right)=d_{t} y_{t}=\delta d_{t-1} y_{t-1} \Longrightarrow P V_{0}\left(y_{t}\right)=\delta^{t} y_{0} \Longrightarrow P V_{0}\left(c_{t}^{l}\right)=\left(1-s_{t}^{l}\right) \delta^{t} y_{0}
$$

Therefore, the present value of the stream of output $\mathbf{y} \equiv\left\{y_{t}\right\}_{t=0}^{\infty}$ is deterministic and equal to

$$
P V_{0}(\mathbf{y})=\frac{y_{0}}{1-\delta} \Longrightarrow P V_{0}\left(\mathbf{c}^{l}\right)=y_{0} \sum_{t=1}^{\infty} \delta^{t}\left(1-s_{t}^{l}\right) \text { and } \bar{v}_{0}=\frac{\delta(1-\rho)}{1-\delta} y_{0}
$$

The intertemporal budget constraint of the consumer is well defined

$$
P V_{0}\left(\mathbf{c}^{l}\right)=\bar{v}_{0}^{l}+\bar{\pi}_{0}^{l}+i_{0}^{k} k_{0}^{l}+(1-\gamma) \rho \frac{y_{0}}{1-\delta}=\frac{\left(1-s^{*}\right) y_{0}}{1-\delta}
$$

where the second equality holds by the representative consumer assumption. Substituting for $P V_{0}\left(\mathbf{c}^{l}\right)$, we find that, on every path, savings must satisfy

$$
\sum_{t=0}^{\infty} \text { weight }_{t}\left(1-s_{t}^{l}\right)=1-s^{*}, \text { where } \text { weight }_{t} \equiv \delta^{t}(1-\delta), \text { and } \sum_{t=0}^{\infty} \text { weight }_{t}=1 \text {. }
$$

Let $\mathcal{S}_{2}^{l}$ be the set of all savings that satisfy this property. Note that every element $\mathbf{s}^{l} \in \mathcal{S}_{2}^{l}$ of is deterministic, unlike the set of all Euler paths $\mathcal{S}_{1}^{l}$ whose elements are stochastic processes. The set of all Euler path $\left(\mathbf{s}^{l} \in \mathcal{S}_{1}^{l}\right)$ which are feasible (all realisations of $\mathbf{s}^{l}$ belong to $\mathcal{S}_{2}^{l}$ ) has been labelled $\mathcal{S}^{l}$. A feasible Euler programme $\mathbf{s}^{l}$ can be characterised by the distribution of probability it induces on $\mathcal{S}_{2}^{l}$. Hence, the utility of a consumption programme $\mathbf{s}^{l} \in \mathcal{S}^{l}$ is

$$
\begin{aligned}
U\left(\mathbf{s}^{l}\right) & =\mathcal{E}_{0}\left[\sum_{t=0}^{\infty} \delta^{t} \log \left(1-s_{t}^{l}\right)\right]+\text { cste } \\
& =\int_{\mathbf{s}^{l} \in \mathcal{S}_{2}^{l}} \sum_{t=0}^{\infty} \delta^{t} \log \left(1-s_{t}^{l}\right) d \operatorname{Pr}\left(\mathbf{s}^{l}\right)+\text { cste } \\
& =\int_{\mathbf{s}^{l} \in \mathcal{S}_{2}^{l}} \bar{U}\left(\mathbf{s}^{l}\right) d \operatorname{Pr}\left(\mathbf{s}^{l}\right)+\text { cste },
\end{aligned}
$$

where the notation $\bar{U}$ is meant to emphasize its deterministic nature. Let us note that the elements of $\mathcal{S}_{2}^{l}$ are barycenters of $1-s^{*}$ with weights $\left\{\text { weight }_{t}\right\}_{t=0}^{\infty}$, i.e. their weighted average is equal to $1-s^{*}$. A well-known property of a concave function $f$ is that, if $\left\{x_{i}\right\}_{i \in I}$ are barycenters of $\bar{x}$ with weights $\left\{w_{e i g h t}\right\}_{i \in I}$, then

$$
\sum_{i \in I} \text { weight }_{i} f\left(x_{i}\right) \leq f(\bar{x}) .
$$


Since $\log$ is a concave function, for all $\mathbf{s}^{l} \in \mathcal{S}_{2}^{l}$,

$$
\begin{aligned}
& \sum_{t=0}^{\infty} \delta^{t}(1-\delta) \log \left(1-s_{t}^{l}\right) \leq \sum_{t=0}^{\infty} \delta^{t}(1-\delta) \log \left(1-s^{*}\right)=\log \left(1-s^{*}\right) \\
\Longrightarrow & \forall \mathbf{s}^{l} \in \mathcal{S}_{2}^{l}, \quad \bar{U}\left(\mathbf{s}^{l}\right) \leq \bar{U}\left(\mathbf{s}^{*}\right) .
\end{aligned}
$$

Substituting this inequality into (14) yields for all Euler feasible paths (in $\mathcal{S}^{l}$ )

$$
\begin{aligned}
\forall \mathbf{s}^{l} \in \mathcal{S}^{l}, \quad U\left(\mathbf{s}^{l}\right) & =\int_{\mathbf{s}^{l} \in \mathcal{S}_{2}^{l}} \bar{U}\left(\mathbf{s}^{l}\right) d \operatorname{Pr}\left(\mathbf{s}^{l}\right)+\text { cste } \\
& \leq \int_{\mathbf{s}^{l} \in \mathcal{S}_{2}^{l}} \bar{U}\left(\mathbf{s}^{*}\right) d \operatorname{Pr}\left(\mathbf{s}^{l}\right)+\text { cste } \\
& =\bar{U}\left(\mathbf{s}^{*}\right)+\text { cste } \\
& =U\left(\mathbf{s}^{*}\right) .
\end{aligned}
$$

Since the consumption programme $\mathbf{s}^{*}$ belongs to the feasible set $\mathcal{S}^{l}$, it is the optimal programme and the consumer $l$ will choose $\forall t \geq 0, \quad s_{t}^{l}=s^{*}$. Q.E.D.

\subsubsection{Stock market valuation}

Valuation through the intertemporal budget constraint We have established that

$$
P V_{0}(\mathbf{c})=\frac{c_{0}}{1-\delta}=\frac{\left(1-s^{*}\right) y_{0}}{1-\delta}, \text { and } P V_{0}(\mathbf{w})=\frac{(1-\gamma) \rho y_{0}}{1-\delta} .
$$

Substituting for these present values in the intertemporal budget constraint (8), we obtain

$$
\begin{aligned}
\frac{\left(1-s^{*}\right) y_{0}}{1-\delta} & =\bar{v}_{0}+(1-\rho) y_{0}+\gamma \rho y_{0}+\frac{(1-\gamma) \rho y_{0}}{1-\delta} \\
\Longrightarrow \bar{v}_{0} & =\bar{v}_{0}^{*} \equiv \frac{(1-\rho) \delta}{1-\delta} y_{0}=\frac{\delta(1-\rho)}{1-\delta} \theta_{0} k_{0}^{\gamma}
\end{aligned}
$$

Suppose that initially the price of the market portfolio is higher than its equilibrium value

$$
\bar{v}_{0}=\bar{v}_{0}^{*}+\Delta v .
$$

The consumer will want to spread this extra value $\Delta v$ as consumption over his infinite life time, and we would have from (8)

$$
\begin{aligned}
P V_{0}(\mathbf{c}) & =\bar{v}_{0}^{*}+\Delta v+\bar{\pi}_{0}+i_{0}^{k} k_{0}+P V_{0}(\mathbf{w}) \\
& =\Delta v+\frac{\delta(1-\rho)}{1-\delta} y_{0}+(1-\rho) y_{0}+\gamma \rho y_{0}+\frac{(1-\gamma) \rho y_{0}}{1-\delta} \\
& =\Delta v+\frac{1-s^{*}}{1-\delta} y_{0} .
\end{aligned}
$$


Since

$$
P V_{0}(\mathbf{c})=\frac{c_{0}}{1-\delta}
$$

we would have

$$
c_{0}=(1-\delta) \Delta v+\left(1-s^{*}\right) y_{0} .
$$

i.e. consumption plus investment demand would exceed output

$$
c_{0}+k_{1}=y_{0}+(1-\delta) \Delta v,
$$

which is clearly incompatible with market clearing.

Valuation through the Euler equation The Euler equation (9), here interpreted as the no-subjective arbitrage condition, applied to the market return yields

$$
\frac{1}{c_{t}}=\mathcal{E}_{t}\left[\frac{\delta \bar{t}_{t+1}}{c_{t+1}}\right]
$$

Since the real return on the market portfolio is

$$
\bar{v}_{t+1}=\frac{\bar{v}_{t+1}+\bar{\pi}_{t+1}}{\bar{v}_{t}}=\frac{\bar{v}_{t+1}+(1-\rho) y_{t+1}}{\bar{v}_{t}},
$$

the Euler equation becomes, keeping in mind the fact that $s_{t}=s^{*}$,

$$
\frac{1}{\left(1-s_{t}\right) y_{t}}=\mathcal{E}_{t}\left[\frac{\delta\left(\bar{v}_{t+1}+(1-\rho) y_{t+1}\right)}{\left(1-s_{t+1}\right) y_{t+1} \bar{v}_{t}}\right] \Longrightarrow \frac{\bar{v}_{t}}{y_{t}}=(1-\rho) \delta+\delta \mathcal{E}_{t}\left[\frac{\bar{v}_{t+1}}{y_{t+1}}\right] \text {. }
$$

Hence, using the method of repeated substitutions, we obtain

$$
\frac{\bar{v}_{t}}{y_{t}}=\left[1+\delta+\cdots+\delta^{\tau}\right](1-\rho) \delta+\delta^{\tau+1} \mathcal{E}_{t}\left[\frac{\bar{v}_{t+\tau+1}}{y_{t+\tau+1}}\right] .
$$

Hence, we can see that the equilibrium

$$
\frac{\bar{v}_{t}}{y_{t}}=\frac{\bar{v}_{t}^{*}}{y_{t}}=\frac{(1-\rho) \delta}{1-\delta},
$$

corresponds to the transversality condition

$$
\lim _{\tau \longrightarrow \infty} \delta^{\tau+1} \mathcal{E}_{t}\left[\frac{\bar{v}_{t+\tau+1}}{y_{t+\tau+1}}\right]=0 .
$$




\subsubsection{Individual stock valuation}

Applying once more the Euler equation (9) to individual stock $n$ yields

$$
\frac{1}{c_{t}}=\mathcal{E}_{t}\left[\frac{\delta i_{t+1}^{n}}{c_{t+1}}\right] \text {. }
$$

Since the real return on the stock is

$$
i_{t+1}^{n}=\frac{v_{t+1}^{n}+\pi_{t+1}^{n}}{v_{t}^{n}}=\frac{v_{t+1}^{n}+u_{n, t+1} \varphi_{n, t+1}^{\nu}(1-\rho) y_{t+1}}{v_{t}^{n}},
$$

the Euler equation becomes once more

$$
\frac{v_{t}^{n}}{y_{t}}=(1-\rho) \delta \mathcal{E}_{t}\left[u_{n, t+1} \varphi_{n, t+1}^{\nu}\right]+\delta \mathcal{E}_{t}\left[\frac{v_{t+1}^{n}}{y_{t+1}}\right] .
$$

Hence, using the method of repeated substitutions, we obtain

$$
\frac{v_{t}^{n}}{y_{t}}=(1-\rho) \delta\left[\mathcal{E}_{t}\left[u_{n, t+1} \varphi_{n, t+1}^{\nu}\right]+\cdots+\delta^{\tau} \mathcal{E}_{t}\left[u_{n, t+\tau+1} \varphi_{n, t+\tau+1}^{\nu}\right]\right]+\delta^{\tau+1} \mathcal{E}_{t}\left[\frac{v_{t+\tau+1}^{n}}{y_{t+\tau+1}}\right] .
$$

The transversality condition for the market portfolio (15) yields the transversality condition for every stock

$0=\lim _{\tau \longrightarrow \infty} \delta^{\tau+1} \mathcal{E}_{t}\left[\frac{\bar{v}_{t+\tau+1}}{y_{t+\tau+1}}\right]=\lim _{\tau \longrightarrow \infty} \delta^{\tau+1} \sum_{n=1}^{N} \mathcal{E}_{t}\left[\frac{v_{t+\tau+1}^{n}}{y_{t+\tau+1}}\right] \Longrightarrow \lim _{\tau \longrightarrow \infty} \delta^{\tau+1} \mathcal{E}_{t}\left[\frac{v_{t+\tau+1}^{n}}{y_{t+\tau+1}}\right]=0$

as no component of the sum can be strictly negative. Therefore, we have

$$
\begin{aligned}
v_{t}^{n} & =(1-\rho) \delta\left(\sum_{\tau=0}^{\infty} \delta^{\tau} \mathcal{E}_{t}\left[u_{n, t} \varphi_{n, t+\tau}^{\nu}\right]\right) y_{t} \\
& =(1-\delta)\left(\sum_{\tau=0}^{\infty} \delta^{\tau} \mathcal{E}_{t}\left[u_{n, t} \varphi_{n, t+\tau}^{\nu}\right]\right) \bar{v}_{t} .
\end{aligned}
$$

Notice that, since

$$
\sum_{n=1}^{N} u_{n, t} \varphi_{n, t+\tau}^{\nu}=\sum_{n=1}^{N} u_{n, t} \frac{\theta_{n, t}^{\nu}}{\theta_{t}^{\nu}}=1 \text { and } \sum_{\tau=0}^{\infty}(1-\delta) \delta^{\tau}=1
$$

aggregating over the number of firms leads to the identity

$$
\sum_{n=1}^{N} \frac{v_{t}^{n}}{\bar{v}_{t}}=1
$$

Also, note that a firm, which has the same prospect for technological progress as the economy average, will be worth $u_{n, t}$ of the capitalised market value

$$
\forall \tau \geq 0, \mathcal{E}_{t}\left[u_{n, t} \varphi_{n, t+\tau}^{\nu}\right]=1 \Longrightarrow v_{t}^{n}=u_{n, t} \bar{v}_{t}
$$




\subsection{Implications of stock market valuation along the $\mathrm{RE}$ path}

Technological progress at the aggregate level Expected jumps in the productivity $\theta_{t}$ do not affect the aggregate valuation of equity. The valuation occurs as a share of current output which increases only with the rate of profit in the economy and with the discount factor.

Technological progress for individual firms (sectors) If the productivity of a firm is expected to jump in the future compare to the average (jump in $\left.\varphi_{n, t+\tau}\right)$, the value of equity in this firm will also jump, the jump being discounted at the rate $\delta$. The previous remark implies that the increase in the value of the firm expected to experience technological progress must be accompanied by a decrease in the value of the rest of the market, as aggregate value remains constant.

Increase in the relative demand for an individual product An increase in the relative share $\left(u_{n, t}\right)$ of demand for a product has the same qualitative effect as an increase in the productivity of the firm.

Equity vs output The value of equity with respect with output is given by

$$
\bar{v}_{t}=\frac{\delta \nu}{(1-\delta)(1+\nu)} y_{t}
$$

where $\nu$ is the rate of profit. When the discount rate is close to 1 , the equity multiplier can be quite large.

Conclusion 1 Only relative technological progress (and changes in the relative share of demand) affects stock market valuation. Aggregate technological progress cannot affect the equity multiplier, hence, it cannot explain rising stock market values in a closed economy.

\section{References}

Abadir, K.M. and G. Talmain, "Aggregation and Persistence in a Macromodel," University of York WP 98-19, 1998.

Arrow, K.J., "Le Rôle des Valeurs Boursières pour la Répartition la Meilleure de Risques," Econometrie, 11, 1953, 41-47.

Greenwood, J. and B. Jovanovic, "The Information-Technology Revolution and the Stock-Market," American Economic Review, 89 (2), 1999, 116-122.

Magill, M. and M. Quinzii, Theory of Incomplete Markets, vol. 1. Cambridge, MA: MIT press, 1996.

Radner, R., "Existence of Equilibrium of Plans, Prices, and Price Expectations in a Sequence of Markets," Econometrica, 40 (2), 1972, 289-303. 
Talmain, G., "On the Number of Currencies Needed to Implement the Complete Asset Market Allocation," Journal of Mathematical Economics, 31, 1999, 251-263.

Zeira, J., "Informational Overshooting, Booms, and Crashes," Journal of Monetary Economics; 43(1), 1999, 237-57. 